\title{
Serum chemerin level, cytokine profile and nutritional status in children with cystic fibrosis
}

\author{
Katarzyna Sznurkowska1 ${ }^{\otimes}$, Katarzyna Kaźmierska1, Tomasz Śledziński², Maciej Zagierski ${ }^{1}$, \\ Anna Liberek ${ }^{3}$ and Agnieszka Szlagatys-Sidorkiewicz ${ }^{1}$
}

'Department of Pediatrics, Pediatric Gastroenterology, Allergology and Nutrition, Medical University of Gdańsk, Gdańsk, Poland; ${ }^{2}$ Department of Pharmaceutical Biochemistry, Medical University of Gdańsk, Gdańsk, Poland; 'Faculty of Health Sciences with Subfaculty of Nursing, Medical University of Gdansk, Gdańsk, Poland

Background: Cystic fibrosis (CF) is characterized by malnutrition and chronic inflammation predominantly occurring in lungs. Evidence suggests a relation between inflammatory activity and nutritional status. Proinflammatory cytokines, playing crucial role in pulmonary destruction in $\mathrm{CF}$, are regarded as a component of the pathogenesis of illness-related malnutrition. Chemerin - a novel marker of a crosstalk between nutrition and inflammation, has not been investigated in children with cystic fibrosis. The aim of this study was to determine serum level of chemerin, interleukin-1b (IL-1b), interleukin-6 (IL-6), tumor necrosing factor a (TNF-a) and interleukin-10 (IL-10) and to verify if they correlate with the nutritional status in children with CF. Methods: The study included 72 pediatric patients with cystic fibrosis. The control group was comprised of 30 healthy children. Nutritional status parameters: Body Mass Index (BMI), fat mass percentage (FM\%) and fat free mass percentage (FFM\%) have been assessed in all the subjects basing on bioimpedance and anthropometry according to Slaughter. Serum concentrations of chemerin and cytokines were estimated with ELISA. Results: No statistically significant difference in serum chemerin was found between the studied and the control group. We have documented a significantly higher level of IL-1b, IL-6, TNF-a and IL-10 in CF patients when compared to healthy controls. Neither the chemerin nor the cytokine levels correlated with parameters of nutritional status in our cohort. No statistically significant correlation was found between the serum chemerin and the inflammatory cytokines: IL-1b, IL-6, and TNFa. Conclusions: Our results show that chemerin is not associated with the nutritional status in children with cystic fibrosis. Chemerin has no impact on the levels of IL-1b, IL- 6 , TNFa in CF patients. IL-1b, IL6, TNFa and also IL10 are upregulated in cystic fibrosis.

Key words: chemerin, interleukin-1b, interleukin-6, tumor necrosis factor a, interleukin-10, cystic fibrosis

Received: 06 August, 2019; revised: 26 September, 2019; accepted: 04 october, 2019; available on-line: 14 November, 2019

母e-mail: k.sznurkowska@gumed.edu.pl

Abbreviations: CF, cystic fibrosis; IL, interleukin; TNFa, tumor necrosis factor a; BMI, Body Mass Index; FFM\%, Fat Free Mass percentage; FM\%, Fat Mass percentage; hsCRP, highly sensitive C-reactive protein; SDS, standard deviation score; BIA, bioimpedance analysis

\section{INTRODUCTION}

Cystic fibrosis (CF) is the most commonly inherited fatal disease affecting Caucasians. This multiorgan progressive disorder is characterized by chronic inflammation and malnutrition, which has been proven to have an impact on the course and prognosis of the disease (Culhane et al., 2013; Roesch et al., 2018).

Malnutrition in CF is related to several factors, such as reduced energy intake resulting from anorexia or lipid maldigestion, increased energy loss associated with gastroesophageal reflux, and increased energy requirement due to pulmonary destruction increasing the respiratory effort (Pencharz \& Durie, 2000). Also, inflammatory activity is suggested as a component of the pathogenesis of illness-related malnutrition (Olveira et al., 2015). Nutritional assessment, early identification of malnutrition, and prompt initiation of supportive treatments are essential parts of the CF patients' care (Gaskin, 2013).

Activation of inflammation predominantly takes place in the CF lungs. Cystic fibrosis pulmonary disease was primarily believed to result from failure of airways to clear bacteria due to retention of thick, sticky mucus, as a result of the exocrine dysfunction (Ratjen, 2009). Evidence suggests that airway inflammation in CF is also associated with increased production of pro-inflammatory cytokines by airway epithelial cells, macrophages, and predominantly neutrophils (Courtney et al., 2004). Several studies have found elevated concentrations of proinflammatory cytokines, such as interleukin-1 (IL-1), interleukin-6 (IL-6), interleukin-8 (IL-8), and tumor necrosis factor-alpha $(\mathrm{TNF} \alpha)$ in the sputum, bronchoalveolar lavage fluid (BALF) and also in the serum of patients with CF (Richman-Eisenstat et al., 2004). Moreover, there is an existing evidence for the presence of increased inflammatory markers also in the absence of CF-related pathogens (Khan et al., 1995; Balough et al., 1995). Some authors have postulated that proinflammatory- anti-inflammatory imbalance in the lungs responsible for sustaining inflammation in the pulmonary tissue is an important element of pathogenesis of the disease (Bonefield et al., 1995; Saadane et al., 2005).

It has been now clearly demonstrated that nutritional status influences the immune cell function and that, conversely, the immune cell function determines the cellular metabolic state (Alwarawrah et al., 2018). Although the mechanisms explaining relations between the pulmonary inflammation and malnutrition in $\mathrm{CF}$ have not been yet elucidated, proinflammatory cytokines are proposed to be the main players (Alwarawrah et al., 2018). A positive relation between cytokines 
and malnutrition has been previously demonstrated in other conditions - predominantly in malignancies (Seruga et al., 2008). Studies concerning the impact of malnutrition on cytokine secretion produced conflicting results, but majority of them report an immunosuppressive influence of weight loss (Gonzales Torres et al., 2013; Azavedo et al., 2005; Muñoz et al., 1994).

In obesity, which contrary to malnutrition has been proven to promote inflammation, many substances produced by the adipose tissue have been shown to exert proinflammatory activity.

One of the novel markers involved in the specific crosstalk between metabolism and immunity is chemerin, regarded as a stimulator of inflammation in obese subjects (Ernst \& Sinal, 2010; Hart \& Greaves, 2010). Chemerin has not been yet investigated in nonobese patients with cystic fibrosis.

The aim of the study was to assess serum concentrations of chemerin, proinflammatory cytokines and interleukin 10, and to verify if they are related to nutritional status in patient with cystic fibrosis.

\section{PATIENTS AND METHODS}

Patients and controls. Seventy two children, aged 9 months to 18 years (median age 9 years 5 months), previously diagnosed with cystic fibrosis, and being under specialist outpatient unit care, were enrolled into the study. Diagnosis was based on the chlorine sweat test and confirmed by genetic testing. Patients did not present with the signs of acute infection at evaluation, all had stable disease and no prior systemic steroid treatment. Thirty healthy children (9 months to 17 years, median age 10 years) constituted the control group.

Peripheral venous, 5-ml, blood samples were collected from all the subjects to determine the chemerin and cytokines levels. Highly sensitive C-reactive protein (hsCRP), was also tested in all the participants. Anthropometric measurements and bioimpedance analysis were performed for all subjects. Clinical and demographic characteristics of the subjects in the studied and control group are shown in Table 1.

\section{METHODS}

Nutritional status. The following parameters were used to evaluate nutritional status: BMI, the percentage of body fat $(\mathrm{FM} \%)$ and fat free mass percentage (FFM \%).

$\mathrm{BMI}$ was expressed as BMI percentile (BMI pc) and as standard deviation score (SDS). Nutrition of all patients was assessed according to the WHO criteria (World Health Organization, 2006). As only 4 patients in the studied group presented with malnutrition in this meaning finally, for the purpose of presented analysis the subjects demonstrating $\mathrm{BMI}<1.5 \mathrm{SD}$ were regarded as undernourished.

FM $\%$ and $\mathrm{FFM} \%$ were assessed based on both: the anthropometric and bio-impedance analysis. Anthropometry was performed using skinfold thickness measurements and standard equations, as described by Slaughter (Slaughter et al., 1998).

Bioimpedance analysis (BIA) was applied using the Maltron model BIO SCAN 920-2.

Cytokines and chemerin. Serum samples from subjects (72 patients with CF and 30 healthy controls) were tested with commercially available enzyme-linked
Table 1. Clinical and demographic characteristics of the subjects in the studied and control group.

\begin{tabular}{|c|c|c|}
\hline & $\begin{array}{l}\text { CF patients } \\
(\mathrm{n}=72) \\
\text { median (range) }\end{array}$ & $\begin{array}{l}\text { Healthy controls } \\
(\mathrm{n}=30) \\
\text { median (range) }\end{array}$ \\
\hline Age & $\begin{array}{l}9.4 \text { years } \\
(9 \text { months- } 18 \text { years })\end{array}$ & $\begin{array}{l}10 \text { years } \\
(9 \text { months }-17 \text { years })\end{array}$ \\
\hline Sex & $\begin{array}{l}\text { girls } n=40(55 \%) \\
\text { boys } n=32(45 \%)\end{array}$ & $\begin{array}{l}\text { girls } n=12(40 \%) \\
\text { boys } n=18(60 \%\end{array}$ \\
\hline BMI percentile & $\begin{array}{l}34 \\
(1-97)\end{array}$ & $\begin{array}{l}66.5 \\
(1-98)\end{array}$ \\
\hline BMI SDS & $\begin{array}{l}-0.39 \\
(-2.32 \pm 1.88)\end{array}$ & $\begin{array}{l}0.42 \\
(-2.32 \pm 2.05)\end{array}$ \\
\hline $\begin{array}{l}\text { FM\% (anthropo- } \\
\text { metric) }\end{array}$ & $\begin{array}{l}23.38 \\
(8.54-42.86)\end{array}$ & $\begin{array}{l}30.9 \\
(17.74-55.62)\end{array}$ \\
\hline $\begin{array}{l}\text { FFM\% (anthropo- } \\
\text { metric) }\end{array}$ & $\begin{array}{l}76.6 \\
(57.13-91.45)\end{array}$ & $\begin{array}{l}69.0 \\
(44.37-82.25)\end{array}$ \\
\hline $\mathrm{FM} \% \mathrm{BIA}$ & $\begin{array}{l}16.21 \\
(7.11-35.44)\end{array}$ & $\begin{array}{l}17.93 \\
(3.8-34.55)\end{array}$ \\
\hline $\mathrm{FFM} \% \mathrm{BIA}$ & $\begin{array}{l}83.73 \\
(2.64-91.08)\end{array}$ & $\begin{array}{l}82.06 \\
(66.5-96.21)\end{array}$ \\
\hline$<1.5 \mathrm{SD}$ & $\mathrm{N}=11(15 \%)$ & $\mathrm{N}=3(10 \%)$ \\
\hline hsCRP & $\begin{array}{l}0.39 \mathrm{mg} / \mathrm{l} \\
(0.2-31.79)\end{array}$ & $\begin{array}{l}0.36 \\
(0.2-6.25)\end{array}$ \\
\hline Stool elastase 1 & $\begin{array}{l}15 \mu \mathrm{g} / \mathrm{g} \\
(5-421)\end{array}$ & Not performed \\
\hline $\begin{array}{l}\text { Cystic fibrosis } \\
\text { mutations }\end{array}$ & $\begin{array}{l}\Delta \mathrm{F} 508 \mathrm{~N}=65 \\
\text { non } \Delta \mathrm{F} 508 \mathrm{~N}=7\end{array}$ & Not applicable \\
\hline
\end{tabular}

immunosorbent assays (ELISA) for IL-1b, IL-6, TNF $\alpha$, IL-10 (R\&D Systems, USA) and for chemerin (Merck Millpore, Germany) in line with the manufacturer's instructions.

Statistics. The significance of differences between the studied and control groups was verified with Mann-Whitney U-test. Correlation analysis was performed by Spearman rank sum test. Chi square test was used to search for associations between categorical variables. The results of all tests were considered significant at $p<0.05$. All analyses were performed with Statistica 10 software (Stat Soft. Inc., USA).

Ethics. The protocol of the study was approved by an independent institutional bioethical board. The study was conducted according to the principles of the Declaration of Helsinki. Informed consent was obtained from legal guardians of all the study participants and from patients older than 15 years.

\section{RESULTS}

\section{Nutritional status}

We found a statistically significant difference for BMI, BMI pc, $\mathrm{FM}_{\%} \%$ and $\mathrm{FFM} \%$ between the studied and the control group. BMI, BMI $\mathrm{pc}$ and $\mathrm{FM} \%$ was 

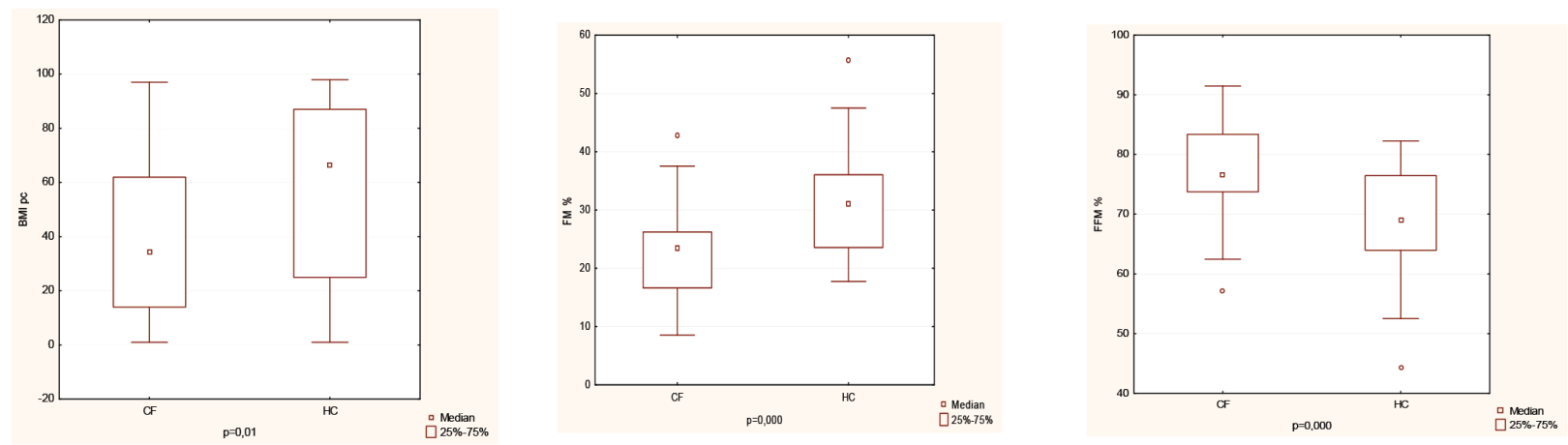

Figure 1. Differences between parameters of nutritional status between the studied group of cystic fibrosis patients (CF) and healthy controls $(\mathrm{HC})$.

$\mathrm{BMI}$ pc, body mass index percentile; FM\%, fat mass percentage measured by anthropometry; FFM\%, fat free mass percentage measured by anthropometry

lower, while $\mathrm{FFM} \%$ was higher in the studied than in the control group, as shown in Fig. 1.

The differences were noted only for FM\% and $\mathrm{FFM} \%$ determined by the means of anthropometry, while bioimpedance measurements results revealed no statistically significant differences ( $p=0.29$ and $p=0.40$, respectively).

Only 4 children in the studied group, and 3 in the control group presented with $\mathrm{BMI}<-2 \mathrm{SD}$, which is defined as malnutrition according to the WHO criteria (World Health Organization, 2006). BMI<-1.5 SD was found in $11(15.2 \%)$ children with CF, while in the control group the rate of undernourished children amounted to $10 \%(\mathrm{~N}=3)$. The difference was not statistically significant $(p=0.56)$.

\section{Cytokines}

Statistically significant differences were demonstrated for all the investigated cytokines: IL-1b, IL-6, TNF $\alpha$ and IL-10, showing higher median concentrations of cytokines in CF patients (Fig. 2).
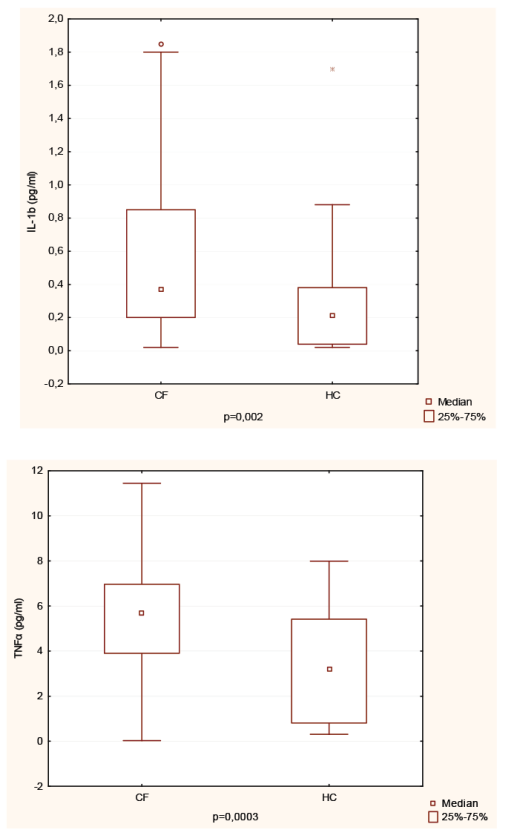

\section{Chemerin}

No statistically significant difference was found between median serum concentration of chemerin in the studied and the control groups $(p=0.87)$.

The relation between cytokines and nutritional status

No statistically significant correlation was found between BMI, BMI percentile, $\mathrm{FM}^{\circ} \%, \mathrm{FFM} \%$ and serum cytokines: IL-1b, IL6, TNF $\alpha$ and IL10. Comparing serum cytokine levels between the groups of different $\mathrm{BMI}:<-1.5 \mathrm{SD}$ and $\mathrm{BMI} \geq-1.5 \mathrm{SD}$ revealed the difference only for IL-6, which was higher in undernourished children $(p=0.01)$ ('Table 2).

The relation between chemerin and nutritional status

No statistically significant correlation was found between BMI, BMI percentile, $\mathrm{FM}^{\circ} \%, \mathrm{FFM} \%$ and chemerin. The groups of different nutritional status $(\mathrm{BMI}<-1.5$ $\mathrm{SD}$ vs $\mathrm{BMI} \geq-1.5 \mathrm{SD})$ did not differ significantly in terms of serum chemerin level $(p=0.11)$ (Table 2$)$.
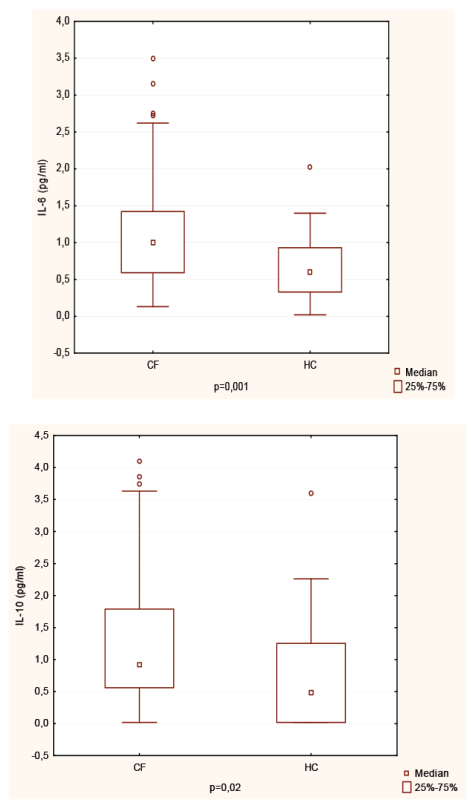

Figure 2. Differences in the levels of cytokines between the studied group of cystic fibrosis patients (CF) and healthy controls (HC). 
Table 2. Differences in the investigated parameters: chemerin, interleukin $1 \mathrm{~b}$, interleukin 6 , tumor necrosis factor a and interleukin 10 between the groups of different nutritional status.

\begin{tabular}{|c|c|c|c|}
\hline & $\begin{array}{l}\mathrm{BMI}<-1.5 \mathrm{SDS} \\
(\mathrm{N}=14) \\
\text { median( range) }\end{array}$ & $\begin{array}{l}\mathrm{BMI} \geq-1.5 \mathrm{SDS} \\
(\mathrm{N}=88) \\
\text { median( range) }\end{array}$ & $p$-value \\
\hline Chemerin & $58.89(44.04-69.84)$ & $49.94(24.7-103.32)$ & 0.11 \\
\hline Interleukin $1 \mathrm{~b}$ & $0.63(0.02-1.85)$ & $0.29(0.02-1.8)$ & 0.05 \\
\hline Interleukin 6 & $1.52(0.23-2.72)$ & $0.78(0.02-6.36)$ & 0.01 \\
\hline TNFa & $5.65(1.49-8.6)$ & $5.07(0.03-11.45)$ & 0.28 \\
\hline Interleukin 10 & $0.89(0.02-4.51)$ & $1.04(0.02-7.47)$ & 0.99 \\
\hline
\end{tabular}

The relation between chemerin and cytokines

No statistically significant correlation was found between serum chemerin level and inflammatory cytokines: IL $1 b$, IL-6, and TNF $\alpha$.

\section{DISCUSSION}

Our results confirm the obvious fact that the nutritional status in CF patients is worse than in healthy controls, although the proportion of malnourished children in the studied group is lower than it could have been expected. These findings reflect the progress that has been made during the last two decades in the treatment of cystic fibrosis (Gaskin, 2013). The impact of malnutrition on the course and the prognosis of the disease has been of great interest since it was proven that low BMI in CF was closely implicated in worsening the lung function, predicted worse outcome, and carried a higher risk of death in patients awaiting lung transplant (Steinkamp \& Wiedemann, 2002; Belkin et al., 2006). Furthermore, improving the nutritional status of malnourished patients may ultimately improve lung function, even in the cohorts with relatively advanced lung disease (Stephenson et al., 2013).

Based on these facts, the efforts of clinicians had focused on effective nutritional treatment strategy, what has been also illustrated by our results in a pediatric cohort. We would like to notice that the mentioned differences in the patients' body composition parameters were found only for anthropometric, and not BIA measurements of $\mathrm{FM} \%$ and $\mathrm{FFM} \%$. The discrepancies between those two methods of body composition evaluation have been previously reported and have shown some advantage of anthropometry over bioelectrical impedance in $\mathrm{CF}$ patients (Alicandro et al., 2015). Consistently with previous results, our study provides further data that proinflammatory cytokines are upregulated in cystic fibrosis (Nicols et al., 2008; Courtney et al., 2004). We found all the investigated serum cytokine levels to be increased in the CF children, although none of the patients presented with acute infection, and hsCRP was not higher in the studied group when compared to healthy controls. This reflects the well-known fact that the persistent inflammatory state is a characteristic feature of cystic fibrosis, irrespective of the stage of the disease and presence of bacteria in the airways (Courtney et al., 2004; Wolter et al., 1999). Thus, proinflammatory cytokines can be regarded as inflammatory markers of an ongoing pulmonary progression in CF.

In the study presented here, we did not document statistical correlation between nutritional status and cytokine levels, although inflammatory cytokines are believed to be one of the factors contributing to the disease related malnutrition. However, it is difficult to demonstrate such association, if we realize the complex and multifactorial origin of malnutrition in CF. The role of cytokines as mediators of weight loss and anorexia has been previously proven in studies concerning malignancies, showing apparent relation between the level of IL-6, IL1 and TNF, and neoplasmatic cachexia (Patel \& Patel, 2017; Kuroda et al., 2007). Comparison between the groups of opposed BMI SDS revealed statistically higher serum IL-6 level in the malnourished patients. Similar results were also presented by Santetti, who reported high level of IL-6 in children with chronic liver disease at nutritional risk (Santetti et al., 2015). We have to note that in our study the regarded sample of malnourished children was very small and comprised only 14 subjects presenting $\mathrm{BMI}<-1.5 \mathrm{SD}$. This observation needs to be verified in a larger cohort. Our results also showed an increased IL-10 - the main anti -inflammatory cytokine, which has not been so extensively investigated in CF patients. This may reflect the physiological immunoregulatory function of this cytokine in self-limiting of inflammation. This finding may stand in opposition to the opinion of some authors, who claim that proinflammatory-anti- inflammatory imbalance may be responsible for the pulmonary progressive destruction (Saadane et al., 2005).

Chemerin, the main parameter investigated here, also appeared to be not corelated with the nutritional status in our cohort. Majority of the studies dealing with this issue concerned adult obese patients and demonstrated relation between chemerin and BMI, waist circumference, as well as multiple components of the metabolic syndrome ( $\mathrm{Li}$ et al., 2014). Results of several investigations confirm these associations also in obese children (Śledzińska et al., 2017). In the study presented here, we have aimed to compare malnourished children with the group of children of normal nutritional status, but we documented no statistically significant difference in the chemerin level. It could be expected that chemerin, regarded as a marker of the adipose tissue, should be decreased in children with low BMI. Our results also did not document the relation between chemerin and proinflammatory cytokines, as well as hsCRP, which is inconsistent with previous publications concerning obese children (Landgraf et al., 2012; Śledzińska et al., 2017). We have to note that cystic fibrosis itself is an inflammatory condition induced by strong local triggers, including detectable and undetectable infection or unproper CFTR gene products, which are the main stimulators of inflammation. Thus, the hypothesized association between chemerin and proinflammatory cytokines is difficult to document.

Discrepancies between our results and previous findings may indicate that the described connections between 
chemerin and metabolism, as well as its proinflammatory activity, do not play a prominent role in non-obese patients.

\section{CONCLUSIONS}

Our results show that chemerin concentration is not associated with nutritional status in children with cystic fibrosis. Chemerin has no impact on the levels of IL $1 b$, IL-6, and TNF $\alpha$ in CF patients. IL-1b, IL-6, TNF $\alpha$, as well as IL-10, are upregulated in cystic fibrosis.

\section{REFERENCES}

Battezzati A, Bianchi ML, Loi S, Speziali C, Bisogno A, Colombo C (2015) Estimating body composition from skinfold thicknesses and bioelectrical impedance analysis in cystic fibrosis patients. J Cyst Fibros 14: 784-791. https://doi.org/10.1016/j.jcf.2015.07.011

Alwarawrah Y, Kiernan K, MacIver NJ (2018) Changes in nutritional status impact immune cell metabolism and function. Front Immunol 16: 1055. https://doi.org/10.3389/fimmu.2018.01055

Azevedo ZMA, Luz RA, Victal SH, Kurdian B, Fonseca VM, Fitting C, Câmara FP, Haeffner-Cavaillon N, Cavaillon JM, Gaspar Elsas MI, Xavier Elsas P (2005) Increased production of tumor necrosis factor-a in whole blood cultures from children with primary malnutrition. Braz. J Med Biol Res 38: 171-183. https://doi.org/10.1590/ s0100-879x2005000200005

Balough K, McCubbin M, Weinberger M, Smits W, Arhens R, Fick R (1995) The relationship between infection and inflammation in the early stages of lung disease from cystic fibrosis. Pediatr Pulmonol 20: 63-70. https://doi.org/10.1002/ppul.1950200203

Belkin RA, Henig NR, Singer LG, Chaparro C, Rubenstein RC, Xie SX, Yee JY, Kotloff RM, Lipson DA, Bunin GR (2006) Risk factors for death of patients with cystic fibrosis awaiting lung transplantation. Am J Respir Crit Care Med 173: 659-666. https://doi. org/10.1164/rccm.200410-1369OC

Bonfield TL, Konstan MW, Burfeind P, Panuska JR, Hilliard JB, Berger M (1995) Normal bronchial epithelial cells constitutively produce the anti-inflammatory cytokine interleukin-10, which is downregulated in cystic fibrosis. Am J Respir Cell Mol Biol 13: 257-261. https:// doi.org/10.1165/ajrcmb.13.3.7544594

Courtney JM, Ennis M, Elborn JS (2004) Cytokines and inflammatory mediators in cystic fibrosis. J Cyst Fibros 3: 223-231. https://doi. org/10.1016/j.jcf.2004.06.006

Culhane S, George C, Pearo B, Spoede E (2013) Malnutrition in cystic fibrosis: a review. Nutr Clin Pract 28: 676-683. https://doi. org/10.1177/0884533613507086

Ernst MC, Sinal CJ (2010) Chemerin: at the crossroads of inflammation and obesity. Trends Endocrinol Metab 21: 660-667. https://doi, org/10.1016/j.tem.2010.08.001

Gaskin KJ (2013) Nutritional care in children with cystic fibrosis: are our patients becoming better? Eur J Clin Nutr 67: 558-564. https:// doi.org/10.1038/ejcn.2013.20

González-Torres C, González-Martínez H, Miliar A, Nájera O, Graniel J, Firo V, Alvarez C, Bonilla E, Rodríguez L (2013) Effect of Malnutrition on the Expression of Cytokines Involved in Th1 Cell Differentiation. Nutrients 19: 579-593. https://doi.org/10.3390/ nu5020579

Hart R, Greaves DR (2010) Chemerin contributes to inflammation by promoting macrophage adhesion to VCAM-1 and fibronectin through clustering of VLA-4 and VLA-5. J Immunol 185: 3728-3739. https://doi.org/10.4049/jimmunol.0902154

Khan TZ, Wagener JS, Bost T, Martinez J, Accurso FJ, Riches DW (1995) Early pulmonary infection in infants with cystic fibrosis. Am J Respir Crit Care Med 151: 1075-1082. https://doi.org/10.1164/ ajrccm/151.4.1075

Kuroda K, Nakashima J, Kanao K, Kikuchi E, Miyajima A, Horiguchi Y, Nakagawa K, Oya M, Ohigashi T, Murai M (2007) Interleukin 6 is associated with cachexia in patients with prostate cancer. Urology 69: 113-117. https://doi.org/10.1016/j.urology.2006.09.039
Landgraf K, Friebe D, Ullrich T, Kratzsch J, Dittrich K, Herberth G, Adams V, Kiess W, Erbs S, Körner A(2012) Chemerin as a mediator between obesity and vascular inflammation in children. J Clin Endocrinol Metab 97: E556-E564. https://doi.org/10.1210/jc.20112937

Li Y, Shi B, Li S. (2014) Association between serum chemerin concentrations and clinical indices in obesity or metabolic syndrome: a meta-analysis. PLOS ONE 9 e113915. https://doi.org/doi.org/10.1371/ journal.pone.0113915

Muñoz C, Arévalo M, López M, Schlesinger L (1994) Impaired interleukin-1 and tumor necrosis factor production in protein-calorie malnutrition. Nutr Res 14: 347-352

Nichols D, Chmiel J, Berger M (2008) Chronic inflammation in the cystic fibrosis lung: alterations in inter- and intracellular signaling. Clin Rev Allergy Immunol 34: 146-162. https://doi.org/doi. org/10.1007/s12016-007-8039-9

Olveira G, Olveira C, Gaspar I, Porras N, Martín-Núñez G, Rubio E, Colomo N, Rojo-Martínez G, Soriguer F (2012) Fat-free mass depletion and inflammation in patients with bronchiectasis. J Acad Nutr Diet 112: 1999-2006. https://doi.org/10.1016/j. jand.2012.08.013

Patel HJ, Patel BM (2017) TNF- $\alpha$ and cancer cachexia: Molecular insights and clinical implications. Life Sci 170: 56-63. https://doi. org/10.1016/j.lfs.2016.11.033.3

Pencharz PB, Durie PR (2000) Pathogenesis of malnutrition in cystic fibrosis, and its treatment. Clin Nutr 19: 387-394. https://doi. org/10.1054/clnu.1999.0079

Rajten FA (2009) Cystic fibrosis: pathogenesis and future treatment. Respir Care 54: 595-605. PMID: 19393104

Richman-Eisenstat J (1996) Cytokine soup: making sense of inflammation in cystic fibrosis. Pediatr Pulmonol 21: 3-5. https://doi.org/10.1002/10990496(199601)21:1<3::aid-ppul1950210103>3.0.co;2-b

Roesch EA, Nichols DP, Chmiel JF (2018) Inflammation in cystic fibrosis: An update. Pediatr Pulmonol 53: S30-S50. https://doi. org/10.1002/ppul.24129

SaadaneA, Soltys J, Berger M (2005) Role of IL-10 deficiency in excessive nuclear factor- $x \mathrm{~B}$ activation and lung inflammation in cystic fibrosis transmembrane conductance regulator knockout mice. J Allergy Clin Immunol 115: 405-411. https://doi.org/10.1016/j. jaci.2004.10.044

Santetti D, de Albuquerque Wilasco MI, Dornelles CT, Werlang IC, Fontella FU, Kieling CO, Dos Santos JL, Vieira SM, Goldani HA (2015) Serum proinflammatory cytokines and nutritional status in pediatric chronic liver disease. World J Gastroenterol 21: 8927-8934. https://doi.org/10.3748/wjg.v21.i29.8927

Seruga B, Zhang H, Bernstein LJ, Tannock IF (2008) Cytokines and their relationship to the symptoms and outcome of cancer. Nat Rev Cancer 8: 887-899. https://doi.org/10.1038/nrc2507

Slaughter MH, Lohman TG, Boileau RA, Horswill CA, Stillman RJ, Van Loan MD, Bemben DA (1988) Skinfold equations for estimation of body fatness in children and youth. Hum Biol 60: 709-723. PMID: 3224965

Sledzińska M, Szlagatys-Sidorkiewicz A, Brzezinski M, Kaźmierska K, Sledziński T, Kamińska B (2017) Serum chemerin in children with excess body weight may be associated with ongoing metabolic complications - A pilot study. Adv Med Sci 62: 383-386. https://doi. org/10.1016/j.advms.2017.04.002.

Steinkamp G, Wiedemann B (2002) Relationship between nutritional status and lung function in cystic fibrosis: cross sectional and longitudinal analyses from the German CF quality assurance (CFQA) project. Thorax 57: 596-601. https://doi.org/10.1136/tho$\operatorname{rax} .57 .7 .596$

Stephenson AL, Mannik LA, Walsh S, Brotherwood M, Robert R, Darling PB, Nisenbaum R, Moerman J, Stanojevic S (2013)Longitudinal trends in nutritional status and the relation between lung function and BMI in cystic fibrosis: a population-based cohort study $\mathrm{Am}$ J Clin Nutr 97: 872-877. https://doi.org/10.3945/ajcn.112.051409.

Wolter JM, Rodwell RL, Bowler SD, McCormack JG (1999) Cytokines and inflammatory mediators do not indicate acute infection in cystic fibrosis. Clin Diagn Lab Immunol 6: 260-265. PMCID: PMC95697

World Health Organization Multicentre Growth Reference Group (2006) WHO Child Growth Standards based on length/height, weight and age. Acta Ped 450: 76-85. PMID: 16817681 